\title{
OCCUPATIONAL EXPOSURE TO SHARP INJURIES AMONG MEDICAL AND DENTAL HOUSE OFFICERS IN NIGERIA
}

\author{
NOSAYABA OSAZUWA-PETERS ${ }^{1}$, AIMUAMWOSA OBARISIAGBON ${ }^{2}$, \\ CLEMENT C. AZODO ${ }^{3}$, ADEBOLA O. EHIZELE ${ }^{4}$, and OZOEMENE N. OBUEKWE ${ }^{5}$ \\ ${ }^{1}$ Washington University in St. Louis, Missouri, USA \\ Public Health Program, Brown School of Social Work \\ ${ }^{2}$ University of Benin Teaching Hospital, Benin City, Nigeria \\ Department of Oral/Maxillofacial Surgery \\ ${ }^{3}$ University of Benin, Benin City, Nigeria \\ Department of Periodontics \\ ${ }^{4}$ University of Benin Teaching Hospital, Benin City, Nigeria \\ Department of Periodontics \\ ${ }^{5}$ University of Benin Teaching Hospital, Benin City, Nigeria \\ Coordinator of Post-graduate Studies
}

\begin{abstract}
Objective: Sharp injuries constitute important occupational exposure in hospital environment, and perhaps the newly graduated medical and dental students, known as House Officers, in the first twelve months of their practice, are the most vulnerable of all health workers. This study was designed to examine the nature and prevalence of occupational injuries among medical and dental house officers and factors associated with reporting these injuries. Materials and Methods: A self-administered questionnaire was used to obtain information on demography, types of exposure, and barriers to official reporting of occupational injuries. One hundred and forty-four medical and dental house officers in 3 government owned hospitals in Edo State, Nigeria participated in the study, between April and May, 2010. Descriptive and multivariable analyses were performed. Results: The overall response rate was $96 \%$. Out of all participants, $69.4 \%$ were male; $82.6 \%$ were medical house officers. Prevalence of percutaneous injury was $56.9 \%$; where needlestick injury constituted one-third of all injuries. Mean frequency of injury was $1.86 \pm 2.24$, with medicals having more injuries $(\mathrm{p}=0.043)$. The ward was the most common location for the injury and $14.8 \%$ of exposures occurred as a result of lapse in concentration. At least $77.0 \%$ did not formally report their injury and perceived low injury risk was the most common reason given (51.67\%). Conclusion: This study shows that a substantial number of House Officers are exposed to occupational injuries and that the majority of them does not formally report these. Safer work environment may be achieved by implementing adequate educational programs tailored specifically to house officers, and policies encouraging exposure reporting should be developed.
\end{abstract}

\section{Keywords:}

Occupational exposures, Sharp injuries, Needlestick injuries, Medical and dental house officers, Underreporting, Nigeria

Received: January 28, 2012. Accepted: November 8, 2012.

Corresponding author: N. Osazuwa-Peters, Washington University in St. Louis, George Warren Brown School of Social Work, Campus Box 1196, One Brookings Drive, 63130 St. Louis, MO, USA (e-mail: osazuwa-peters@wustl.edu). 


\section{INTRODUCTION}

The working environment of medical professionals can be described as a potential risk zone due to numerous hazards endemic to the environment [1,2]. Numerous occupational hazards faced by medical professionals include exposure to blood and body fluids from sharp and needlestick injuries [2-6]. This has become even more important because of the advent of resistant strains of tuberculosis, HIV, Hepatitis B, and other viral infections $[5,6]$. The prevalence of sharp and needlestick injuries indicates their importance as occupational hazards; out of the estimated 100 million new cases of occupational health issues reported worldwide annually [7], sharp and needlestick injuries are the most common in the health care setting $[2,3]$. Additionally, there is growing evidence that many cases of occupational exposure to blood and body fluids through needlestick and sharps injuries go unreported [8-10] and if reported, they would increase the incidence beyond the reported 100 million annual cases of occupational hazards. One group of medical professionals that are perhaps most vulnerable are the new practitioners, known as House Officers or Interns [11,12]. House Officers (HOs) as used in this study are the newly qualified medical or dental doctors (recent graduates of medical or dental schools) who are employed by hospitals to carry out various procedures, many of which are done under supervision. They usually have four clinical rotations (postings), in total lasting 12 months, and they spend three months in each posting. These postings in case of medical house officers include Internal Medicine, Surgery, Pediatrics, and Obstetrics and Gynecology; while in case of dental house officers they include Oral Surgery/ Pathology, Periodontics, Restorative Dentistry, and Preventive/Community Dentistry.

HOs are peculiar in some respects. Having just graduated from medical or dental school and making the transition from being a student to becoming a newly qualified doctor, they are very enthusiastic about carrying out their duties. They have academic knowledge that is not balanced with actual clinical experience $[13,14]$ Since the practice of medicine involves a level of apprenticeship, many of the duties of HOs expose them rather prematurely to handling potentially hazardous sharp instruments and objects (e.g. setting up lines, venepuncture $[13,15]$, as well as taking blood samples, saliva for laboratory testing, and tissues for biopsies). Additionally, dental HOs administer local anesthetics in procedures like simple tooth extraction, root canal fillings, and restorations; and they use instruments such as sharp forceps and elevators.

Occurrence of injuries could be attributed to the lack of experience when dealing with uncooperative or aggressive patients. Another factor is inconsistent compliance with preventive measures like the use of gloves and the recapping of the used needles. Lack of handling skills and caution, freak accidents, and iatrogenic incidents often result in sharp injuries and exposure to contaminated body fluids $[13,16,17]$. Sometimes it could be the HOs' anxiety and stress levels [13,18], which may potentially increase the possibility of injuries [19]. Although there are well documented post-exposure protocols, evidence suggests that many HOs, like other members of medical personnel, do not comply with them. Many do not even report these cases, nor do they follow the postexposure protocol $[15,19,20]$. With previous experiences as HOs in Midwestern Nigeria, we can attest to these occurrences. Although the statistics are not documented, anecdotal evidence suggests that not all exposure to blood and body fluids are reported nor are standard post-exposure protocols observed by HOs. And unlike developed nations such as the United States, where estimated annual cases of sharp and needlestick injuries of medical professionals are given [21], Nigeria, like many other developing countries of the world, is bereft of such data [22]. Particularly, data on the nature and frequency of sharp injuries, preventive measures, level of reporting, and use of postexposure protocols specifically among Nigerian HOs is lacking, and this is important in terms of assessing the true nature of the problem. To the best of our knowledge, in 
the literature there is actually no data exclusively on medical and dental HOs in the first 12 months of their practice. This study was a project that aimed to bridge this gap, with the following objectives: to generate baseline data on the nature and prevalence of occupational exposure to blood and body fluids through sharp and needlestick injuries among HOs; to determine the major factors responsible for sharp and needlestick injuries as well as other occupational exposures to blood and body fluids among HOs, and to expose the potential problem of under-reporting of cases of occupational exposure by HOs in order to increase post-exposure monitoring and compliance by hospital authorities. We asked the following research questions: what are the main sharp injuries in HOs? What are the main factors responsible for these injuries? How often do HOs get injured or get exposed to hazardous occupational exposure? And how often do they report injuries and exposures, and how do they follow-up after an exposure to contaminated blood or body fluid?

We predicted that: HOs would be expected to have received most needlestick injuries, due to inexperience in dealing with patient, poor use of protective barriers, and patient factors as the most important factors causing exposures. This is because HOs are involved in many procedures which involve injections and needlesticks. Additional hazardous exposures often result from exposure to aerosol that is generated from restorative and periodontal procedures, which as a result of not wearing face masks can expose them to patients' saliva and blood [23]. We also predicted a correlation between high frequency of exposure, low post-exposure protocol and poor under-reporting.

\section{MATERIALS AND METHODS}

\section{Study design}

For this descriptive cross-sectional survey, male and female HOs were sampled from three hospitals in Edo State offering post-graduate medical and dental training. A selfadministered questionnaire was developed specifically for this study after a thorough literature review, and was pretested on thirty randomly selected medical and dental students of the University of Benin, after which, adjustments were made to the questionnaire used for the study. The selfadministered questionnaire used in the study was made up of 22 items, designed to obtain demographic information, types of occupational exposure, reporting habits, and barriers to official reporting of occupational injuries.

\section{Subjects}

There were 144 participants in this study. The study was emphasized.

\section{Study sites}

The study was carried out in three hospitals in Edo State, Nigeria, spreading across the geopolitical zones of the state, and comprising of 2-tiers of health care delivery: tertiary and secondary. The study was carried out between April and May, 2010.

Site 1: University of Benin Teaching Hospital - A Federal, tertiary health institution in Benin City, Midwestern Nigeria. The hospital is the largest in Midwest of Nigeria, based in Edo-South, and with more than 200 medical and dental HOs across eight clinical postings.

Site 2: Central Hospital Benin City - a State, secondary care hospital in Benin City, Edo-South. The Central hospital is the largest arm of the Hospital Management Board of Edo State, which comprises of up to 10 hospitals, scattered across the state. It is the largest health employer in the State, with up to 100 medical and dental HOs.

Site 3: Irrua Specialist Teaching Hospital, Irrua - a Federal, tertiary care hospital, the largest in Edo Central and Edo North constituencies, and serving these regions of the state. It is a teaching hospital with about $40 \mathrm{HOs}$, all medical.

\section{Human subject concerns}

Approval for this research was obtained from the University of Benin Teaching Hospital ethical review board. Prior 
to participation, participants received verbal and written explanations that their participation was anonymous and voluntary. No identifiers were recorded, and both genders were eligible for participation.

\section{Analysis}

Data was entered in SPSS version 15.0. (SPSS version 15.0: SPSS Inc., Chicago, IL, USA). Descriptive statistics was done to understand the demographic variables, as well as types and causes of injuries, frequency of injuries and rate of their reporting. Bivariate associations between variables will be assessed using Chi-square and independent t-test to understand the association between causes of injuries, rate of their reporting, and factors related to underreporting between the medical and dental groups of house officers. Multivariable analyses in a form of binary logistic regression were performed to assess the association between reporting of occupational injuries (yes or no) and gender and independent variables. $\mathrm{P}<0.05$ was considered as significant.

\section{RESULTS}

In total, there were 144 participants in the study and the response rate amounted to 96\%.There were 100 (69.4\%) males and 44 (30.6\%) females; and majority were medical house officers - 119 (82.6\%), while dental house officers were $25(17.4 \%)$. Of the 144 participants, 56.9\% (82/144) experienced occupational exposure. $60.5 \%$ (72/119) of medical house officers experienced occupational exposure while in case of dental house officers this figure amounted to $40.0 \%$ (10/25). The frequency of injuries ranged between 1 and 5, with estimated mean frequency per year being $1.86 \pm 2.24$, with medical house officers having a significantly higher frequency of injuries than dental house officers $(\mathrm{t}=2.04, \mathrm{df}=142, \mathrm{p}=0.043$ ) (Table 1). Injection needlestick injury accounted for the highest number of exposures; at least one-third of the
Table 1. Estimated mean injuries per year among the participants

\begin{tabular}{|c|c|}
\hline Sample & $\begin{array}{c}\text { Injuries (n/year) } \\
\mathrm{M} \pm \mathrm{SD}\end{array}$ \\
\hline Dental & $1.07 \pm 1.53$ \\
\hline Medical & $2.02 \pm 2.33$ \\
\hline Total & $1.86 \pm 2.24$ \\
\hline
\end{tabular}

$\mathrm{M}$ - mean, SD - standard deviation.

$\mathrm{t}=2.04, \mathrm{df}=142, \mathrm{p}=0.043$.

participants had one or more needlestick injuries in the last 12 months preceding the study. Others included injection ampoule and suture blade injuries (Figure 1). The ward was the most common location for the injury $(55.6 \%)$ and the injury occurred mostly while administering injections (28.4\%). Other favorable situations included drawing blood for tests (17.3\%), and dental extraction (7.4\%). Of the 144 participants, $56.9 \%$ (82/144) experienced occupational exposure after becoming HOs.

Table 2 shows the different factors attributed to the injury. About $14.8 \%$ of exposures were reported as a result of lapse in concentration on the part of the HO, and $12.3 \%$ was due to unexpected patient movement.

More than three-quarters $(77.0 \%)$ of the participants who admitted to have been occupationally exposed did

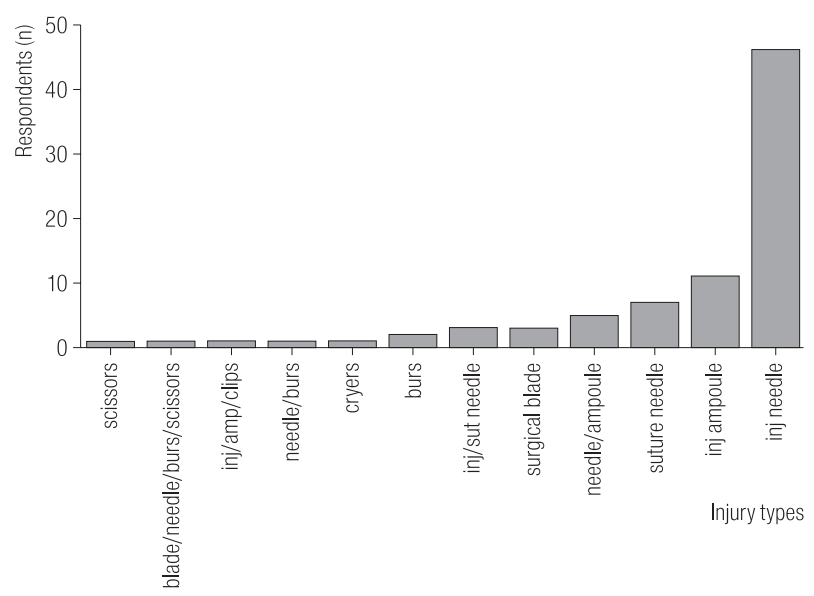

Fig. 1. Types of occupational exposure experienced by House Officers 


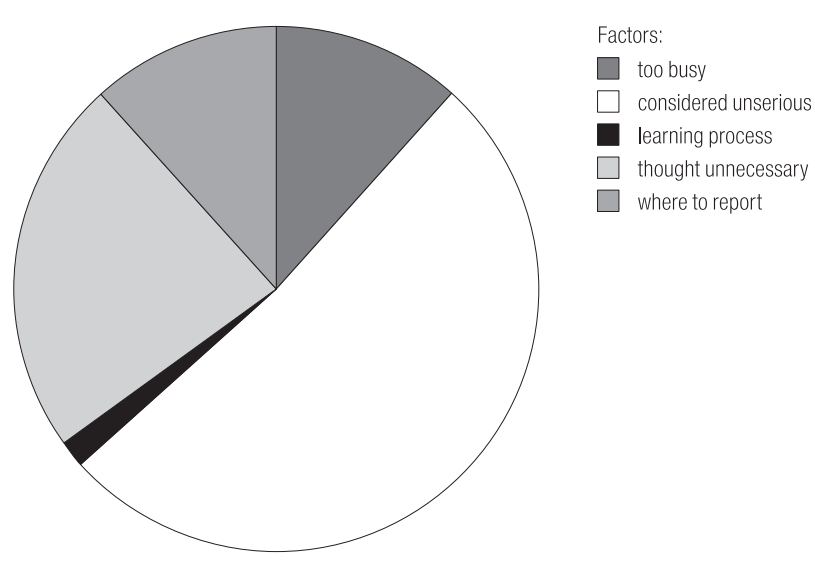

Fig. 2. Underlying factors for underreporting

not formally report their exposure, and $36 \%$ of them claimed they were unaware of the reporting modality of their institutions. The predominant reason given by the respondents for not reporting injuries, however, was perceived lack of seriousness of the injury (Figure 2). Other multivariable analyses were done to identify any

Table 2. Causes of injuries among Medical and Dental House Officers

\begin{tabular}{lc}
\hline \multicolumn{1}{c}{ Causes } & Injuries (\%) \\
\hline Lapse in concentration & 14.8 \\
Unexpected patient movement & 12.3 \\
Uncooperative patient & 8.6 \\
Anxious patient & 8.6 \\
Collision & 8.6 \\
Fatigue & 7.4 \\
Senior colleague presence & 6.2 \\
Carelessness & 6.2 \\
Accidental-colleague & 3.7 \\
Pressure from a patient's relative & 2.5 \\
Poor lighting & 2.5 \\
Lack of time & 2.5 \\
Stress & 1.2 \\
Multiple factors* & 12.2 \\
No response & 2.7 \\
\hline
\end{tabular}

* Multiple factors as used indicate one or more of the other factors above reported together by participants. significant relationships between gender, sex, age, and institution of practice, and no significant association was found between the variables.

\section{DISCUSSION}

To the best of the our knowledge, no previous study has been done on occupational exposure to blood and body fluids among medical and dental HOs as an exclusive group of medical professionals in their first twelve months of practice. This study had 144 participants, out of which 100 were males, which was more than two-third of the population. Although not every HO in the study state participated, this male to female ratio is quite reflective of the paternalistic nature of the medical practice in Nigeria, as observed in other studies $[23,24]$ where female practitioners constituted about $35 \%$ of dental professionals and $19 \%$ of medical professionals, respectively. This study also included $82.6 \%$ of medical HOs and $17.4 \%$ of dental HOs. The overall count of dentists in Nigeria is much lower compared to doctors; however, the figure in this study is lower than the published health manpower information which reports $31.25 \%$ of dentists to $68.75 \%$ of doctors [25].

More than a half of the participants $(56.9 \%)$ had experienced occupational exposure to blood and body fluids, with mean exposure frequency of $1.86 \pm 2.24$. Medical house officers had a significantly higher frequency of injuries than dental house officers. It is important to note that the study was self-reported, so the tendency of social desirability may have biased the result [26], and medical practitioners often tended to report fewer injuries than they actually sustained [27]. Be that as it may, and for the relatively small sample size, $56.9 \%$ represents more than a half of the sample size. Global literature has reported a wide range, between $24 \%$ and $84 \%$ of sharp injuries [12,20,28-30]. Occupational exposure to blood and body fluids is very high among HOs, and this is important because of the danger of cross-infection that this may pose. 
Injection related needlestick injury accounted for at least one-third of participants having experienced a needlestick injury. This is in harmony with several other studies that point to needlestick injuries as the most common form of occupational exposures in healthcare settings both, in Africa as well as in developed regions of the world [30-34]. One explanation that can be given for this high count of needlestick injuries is the poor use of standard precautions like hand gloves, and the practice of recapping the used needles. Literature has shown that many medical practitioners in Nigeria and across the world do not fully understand the concept of standard precautions, and so do not practice them $[9,15,18,35,36]$. The results of this study indicate that the ward is the most common location for injuries and most injuries occurr while administering injections. This differs from a previous study by Shen and Jagger [28] in which most injuries occurr during suturing in the surgical room. Apparently, the HOs in this study were less involved in surgically related duties without supervision and more involved in procedures involving line setting, drawing of blood for tests, administering local anesthetic for simple dental surgeries and other procedures that take place in the ward.

The leading causes of occupational exposures were explored in this study, and the result showed that personal factors appear to be the most frequent reason as $14.8 \%$ of exposures was due to lapse in concentration on the part of the HO. Other studies have reported being in a hurry [21], fatigue or stress due to the long working hours and sleep deprivation due to calls [37], and inferior manual dexterity and carelessness [38] as leading causes of injuries. These factors have broad implications for both educators and institutions; for example, loss of concentration and fatigue due to the long hours may be addressed at the organizational level, and more HOs specific training and reorientation may be needed to improve their perceived self-efficacy and to reduce lapses in concentration.

The challenge of underreporting was also reported in this study. Among participants, $77.0 \%$ admitted to have been occupationally exposed but did not formally report their exposure. The problem of underreporting is very well established in healthcare settings, and there have been reports of between $17 \%$ and $97 \%$ underreporting in previous studies worldwide [32,39,40]. No previous study from Nigeria had discussed reasons for underreporting of injuries; however, literature from the rest of the world gives various reasons for not reporting exposures, from lack of time, to perceived lack of seriousness of the exposures and fear of stigmatization. In this study, perceived lack of seriousness was the most common reason for not reporting injuries and this perceived low risk of injury has been reported as a common reason in several previous studies [40]. This is an erroneous impression as cross-infection is a very serious problem which should not be taken as an esthetic problem among medical personnel. There is also a need for periodic trainings, for example, seminars and workshops on standard precautions and reporting as well as post-exposure modalities, because in this study, $36 \%$ of the participants who did not report injury claimed they were unaware of the reporting modality of their institutions. HOs usually get a week of orientation before resuming duties for the first time, but in the light of this study, there may be a need for more regular programs specifically designed to address these issues.

This research is limited due to its self reporting nature which, could lead to inaccurate estimation of injuries, since there was no independent way of verifying the frequency of injuries or whether or not they were reported to the proper channel. Another limitation is that most of the respondents were mid-way into their 12 months of training, so there was no proper way of assessing whether exposure frequency increased or decreased as the training went on. It will be important to assess this in future studies. A larger sample size may be also needed to corroborate findings from this initial study. This is an important study as it is the first one which focuses exclusively on the nature and prevalence of occupational exposure to blood and body fluids among HOs in their first 12 months of practice. 
In conclusion, this study reported a high frequency of occupational exposures to blood and body fluids, and an alarming rate of underreporting of these exposures to appropriate authorities. In the light of cross-infection control, there is a need for more education and training tailored specifically to this group of professionals, and this training should begin in medical and dental schools as part of the curriculum, and not after graduation. Also, supervision of HOs must improve and their workload and call hours must be reviewed to prevent stress and fatigue which predisposes to exposures. The importance of reporting occupational injuries should be extensively taught and modalities for doing so extremely simplified, to make reporting easier. Cues to action, like posters and frequent advertisements in hospital bulletins are encouraged so that these young professionals can be motivated to change this behavior.

\section{REFERENCES}

1. Patterson WB, Craven DE, Schwartz DA, Nardell EA, Kasmer J, Noble J. Occupational hazards to hospital personnel. Ann Intern Med 1985;102:658-80.

2. Lee LK, Noor-Hassim I. Implication of the prevalence of needlestick injuries in a general hospital in Malaysia and its risk in clinical practice. Environ Health Prev Med 2005;10: 33-41.

3. Ofili AN, Asuzu MC, Okojie OH. Incidence of blood-related work accidents among health workers in a government hospital in Benin City, Nigeria. J Med Biomed Res 2004;3:59-66.

4. Ramos-Gomez F, Ellison J, Greenspan D, Bird W, Lowe S, Gerberding JL. Accidental exposure to blood and body fluids among health care workers in dental teaching clinics: A prospective study. J Am Dent Assoc 1997;128:1253-61.

5. Rapiti E, Pruss-Ustun A, Hutin Y. Sharp injuries: assessing the burden of disease from sharps injuries to health-care workers at national and local levels. WHO environmental burden of disease series, no. 11. Geneve: World Health Organization; 2005.
6. Chia HP, Koh D, Chong R, Jeyaratnam J. A study of needlestick injuries among house officers in a major hospital. Singapore Med J 1994;35:41-3.

7. World Health Organization. Declaration on occupational health for all, Beijing China; 11-14 October 1994; WHO/ OCH 94.1 [cited 2010 March 10]. Available from URL: http://www.who.int/occupational health/publications/declaration/en/index.html.

8. Adegboye AA, Moss GB, Soyinka F, Kreiss JK. The epidemiology of needlestick and sharp instrument accidents in a Nigerian hospital. Infect Control Hosp Epidemiol 1994;15:27-31.

9. McGeer A, Simor AE, Low DE. Epidemiology of needlestick injuries in house officers. J Infect Dis 1990;162:961-4.

10. Pruss-Ustun A, Rapiti E, Hutin Y. Estimation of the global burden of disease attributable to contaminated sharps injuries among health-care workers. Am J Ind Med 2005;48:482-90.

11. Resnic FS, Noerdlinger MA. Occupational exposure among medical students and house staff at a New York City medical center. Arch Intern Med 1995;155:75-80.

12. Lachowicz R, Matthews PA. The pattern of sharps injury to health care workers at Witbank Hospital. SA Fam Pract 2009;51:148-51.

13. Goodfellow PB, Claydon P. Students sitting medical finals ready to be house officers? J R Soc Med 2001;94:516-20.

14. Osborn EHS, Papadakis MA, Gerberding JL. Occupational exposures to body fluids among medical students. A seven-year longitudinal study. Ann Intern Med 1999;130:45-51.

15. Hettiaratchy S, Hassall O, Watson C, Wallis D, Williams D. Glove usage and reporting of needlestick injuries by junior hospital medical staff. Ann R Coll Surg Engl 1998;80:439-41.

16. Khader Y, Burgan S, Amarin Z. Self-reported needle-stick injuries among dentists in north Jordan. East Mediterr Health J 2009;15:185-9.

17. Leggat PA, Kedjarine U, Smith DR. Occupational health problems in modern dentistry: A review. Ind Health 2007;45: 611-21.

18. Sadoh WE, Fawole AO, Sadoh AE, Oladimeji AO, Sotiloye OS. Practice of universal precautions among health care workers. J Natl Med Assoc 2006;98:722-6. 
19. Rabbits JA. Occupational exposure to blood in medical students. S Afr Med J 2003;93:621-4.

20. Patterson JMM, Novak CB, Mackinnon SE, Ellis RA. Needlestick injuries among medical students. Am J Infect Control 2003;31:226-30.

21. Makary MA, Al-Attar A, Holzmueller CG, Sexton JB, Syin D, Gilson MM, et al. Needlestick injuries among surgeons in training. N Engl J Med 2007;356:2693-9.

22. Sagoe-Moses C, Pearson RD, Perry J, Jagger J. Risks to health care workers in developing countries. N Engl J Med 2001;345:538-41.

23. Ogunbodede EO. Gender distribution of dentists in Nigeria, 1981 to 2000. J Dent Educ 2004;68:15-8.

24. Osazuwa-Peters N, Azodo CC, Ehizele AO, Obuekwe ON. Gender differences in characteristics, occupational exposures and infection control practices among dental professionals in Edo state, Nigeria. S Afr J Epidemiol Infect 2012;27(2): 61-5.

25. Scott-Emuakpor A. The evolution of health care systems in Nigeria: which way forward in the twenty-first century. Niger Med J 2010;51:53-65.

26. Arnold HJ, Feldman DC. Social desirability bias in self-report choice situations. Acad Manage J 1981;24:377-85.

27. Au E, Gossage JA, Bailey SR. The reporting of needlestick injuries sustained in theatre by surgeons: are we under-reporting? J Hosp Infect 2008;70:66-70.

28. Shen C, Jagger J, Pearson R. Risk of needle stick and sharp object injuries among medical students. Am J Infect Control 1999;27:435-7.

29. Rosenthal E, Pradier C, Keita-Perse O, Altare J, Dellamonica P, Cassuto JP. Needlestick injuries among French medical students. JAMA 1999;281:1660.

30. Gumodoka B, Favot I, Berege ZA, Dolmans WMV. Occupational exposure to the risk of HIV infection among health care workers in Mwanza region, United Republic of Tanzania. Bull World Health Organ 1997;75:133-40.
31. Adesunkanmi ARK, Badmus TA, Ogunlusi JOD. Accidental injuries and cutaneous contamination during general surgical operations in a Nigerian teaching hospital. East Afr Med J 2003;80:227-34.

32. Tarantola A, Koumaré A, Rachline A, Sow PS, Diallo M, Doumbia S, et al. A descriptive, retrospective study of 567 accidental blood exposures in healthcare workers in three West African countries. J Hosp Infect 2005;60:276-82.

33. Norsayani MY, Noor-Hassim I. Study on incidence of needle stick injury and factors associated with this problem among medical students. J Occup Health 2003;45:172-8.

34. Cervini P, Bell C. Needlestick injury and inadequate post-exposure practice in medical students. J Gen Intern Med 2005;20:419-21.

35. Adebomowo CA, Ezeome ER, Ajuwon JA, Ogundiran TO. Survey of the knowledge, attitude and practice of Nigerian surgery trainees to HIV infected persons and AIDS patients. BMC Surg 2002;2:7.

36. Shariati B, Shahidzadeh-Mahani A, Oveysi T, Akhlaghi H. Accidental exposure to blood in medical interns of Tehran University of Medical Sciences. J Occup Health 2007;49:317-21.

37. Landrigan CP, Rothschild JM, Cronin JW, Kaushal R, Burdick E, Katz JT, et al. Effect of reducing interns' work hours on serious medical errors in intensive care units. N Engl J Med 2004;351:1838-48.

38. Sharma GK, Gilson MM, Nathan H, Makary MA. Needlestick injuries among medical students: incidence and implications. Acad Med 2009;84:1815-21.

39. Medubi SA, Akande TM, Osagbemi GK. Awareness and pattern of needlestick injuries among health workers at University Teaching Hospital Ilorin, Nigeria. Afr J Clin Exp. Microbiol 2006; 7:178-84.

40. Kessler CS, McGuinn M, Spec A, Christensen J, Baragi R, Hershow RC. Underreporting of blood and body fluid exposures among health care students and trainees in the acute care setting: A 2007 survey. Am J Infect Control 2011;39:129-34.

This work is available in Open Access model and licensed under a Creative Commons Attribution-NonCommercial 3.0 Poland License - http://creativecommons.org/ licenses/by-nc/3.0/pl/deed.en. 